WORLD VIEW (Series editor: Emmett T Cunningham Jr)

\title{
Glaucoma in China: how big is the problem?
}

\author{
Paul J Foster, Gordon J Johnson
}

\begin{abstract}
Aims-To derive preliminary estimates for the number of adults in China suffering from glaucoma, and project the burden of visual morbidity attributable to primary and secondary glaucoma.

Methods-Age and sex specific data from two population surveys were applied to US Census Bureau population estimates for urban and rural China. It was assumed that data from Singapore were representative of urban China, and those from Mongolia were representative of rural China.

Results-It was estimated that 9.4 million people aged 40 years and older in China have glaucomatous optic neuropathy. Of this number, 5.2 million (55\%) are blind in at least one eye and 1.7 million (18.1\%) are blind in both eyes. Primary angle closure glaucoma (PACG) is responsible for the vast majority (91\%) of bilateral glaucoma blindness in China. The number of people with the anatomical trait predisposing to PACG (an "occludable" drainage angle) is in the region of 28.2 million, and of these 9.1 million have significant angle closure, indicated by peripheral anterior synechiae or raised intraocular pressure.

Conclusions-This extrapolation of data from two east Asian countries gives an approximate number of people in China suffering from glaucoma. It is unlikely that this crude statistical model is entirely accurate. However, the authors believe the visual morbidity from glaucoma in China is considerable. PACG is probably the leading cause of glaucoma blindness in both eyes, and warrants detailed investigation of strategies for prevention.

(Br F Ophthalmol 2001;85:1277-1282)
\end{abstract}

Glaucoma has long been recognised as a leading cause of blindness, but only recently has it been appreciated how numerically important it is worldwide, and that the scale of the problem will only increase with future population growth and increasing life expectancy.

The epidemiological information available in 1993 in the World Health Organization's (WHO) global data bank on blindness was reviewed by Thylefors and Négrel. ${ }^{1}$ They developed a simple model estimating the number of glaucoma blind people in each World Bank region. Primary open angle glaucoma (POAG) was judged to be responsible for three million blind, primary angle closure glaucoma (PACG) for two million, and for congenital glaucoma the figure was 200 000, giving a total of 5.2 million blind. This represents $15 \%$ of global blindness. The number of people affected by glaucoma was estimated to be about 20 million.

In 1996, Quigley used 111 published reports of glaucoma prevalence to construct a statistical model of the number of people affected by glaucoma worldwide. Data were included only if the study design, methods, and reported results met certain specific criteria. The countries of the world were arranged in seven groups according to similarities in ethnicity and presumed characteristics of glaucoma. For each region, the available age specific prevalence of OAG and ACG were applied to population projections for the year 2000. It was estimated that 66.8 million people were affected by OAG and ACG, with nearly equal numbers of people affected by each disease. Few prevalence studies described secondary glaucoma separately, but an estimate of six million for secondary glaucoma was reached, making a total, without childhood glaucoma, of around 73 million affected. Of these, 6.7 million were thought to be blind. ${ }^{2}$

At that time there were only three studies from east Asia meeting the stipulated criteria. These limited data indicated a linear relation of OAG to age in Asians. It was also assumed that ACG increased with age in a linear fashion, but with a rate three times greater than $O A G$ in Chinese people. The WHO has subsequently amended its projections of glaucoma prevalence in line with Quigley's analysis, suggesting that 6.7 million are blind from glaucoma. This places glaucoma second only to cataract as a cause of world blindness. ${ }^{3}$ Current WHO population estimates suggest that the Asia region is home to 3585 million people ( $61 \%$ of the total population of the world). This number is projected to rise to 5268 million by 2050 (becoming $51 \%$ of the world's population). Clearly, causes of blindness and visual impairment in Asia will exert considerable leverage on the projected totals, and have increasing impact on the socioeconomics of the world's most populous region.

It has been estimated that glaucoma causes blindness in approximately $10 \%$ of those affected. $^{2}$ The importance of glaucoma blindness is compounded by the fact that damage is irreversible, and may progress from 
"definitional" blindness (visual acuity $<3 / 60$ or severely constricted visual fields) to loss of light perception.

Glaucoma in the context of Vision 2020

The "Vision 2020 initiative," described by Thylefors in $1998,{ }^{4}$ and referred to in recent articles in the $\mathrm{BFO}$ by both Taylor and Keeffe $\mathrm{K}^{5}$ and Foster, ${ }^{6}$ is a blueprint for the global elimination of avoidable blindness. It is a joint strategy of the WHO programme for the prevention of blindness and deafness and of the International Agency for the Prevention of Blindness and its constituent non-governmental development organisations. Launched in 1999, it has three essential elements: the control of major causes of blindness; human resource development; and development of infrastructure and appropriate technology.

The causes of blindness, which were prioritised for the first 5 years of the Vision 2020 initiative, were cataract, trachoma, onchocerciasis, childhood blindness, and refractive errors together with the assessment and provision of aid for low vision. The criteria by which this selection was made were these-the disease should cause a large burden of blindness in the world; secondly, that the prevention of blindness on a large scale should be feasible in the present state of knowledge; and, thirdly, that the intervention should be cost effective when compared with the allocation of the same resources to another disease entity.

Although, as we have seen, it is responsible for a large burden of blindness, glaucoma was not included in the priority conditions for the first 5 years. The reason for this was the lack of a proved, practicable approach to the prevention of glaucoma blindness that could be applied to large populations at reasonable cost. While it remains inappropriate to consider screening for POAG on a population basis, ${ }^{78}$ new information on the characteristics and epidemiology of PACG in Asia has made us aware of the potential for detection of those at risk, and possibility of effective prophylaxis.

\section{Advances in the understanding of the epidemiology of glaucoma in Asian people}

A decade ago, data on the epidemiology of glaucoma affecting Asian people appeared somewhat contradictory. Today, several population surveys have shown clear patterns are emerging. Research among Inuit people in Arctic regions gave the first insight to Western ophthalmologists that PACG was a significant cause of ocular morbidity among people of east Asian origin. ${ }^{9-12}$

In $1989 \mathrm{Hu}$ et al examined 10414 (96\% of the target population) residents of Shunyi county, Beijing, 3147 of whom were aged 40 years and over. Sixty two cases of glaucoma were identified in all age groups. PACG accounted for 43 of these, of whom 12 were men and 31 women. There were 11 cases of POAG, nine men and two women. Remarkably, only one of the people suffering POAG was aged over 40 years. The prevalence of primary glaucoma in the over 40 age group was
$1.4 \%$, of which $98 \%$ was PACG. Diagnostic criteria employed may not have been entirely consistent with modern ideas; POAG could have been diagnosed solely on the basis of a raised intraocular pressure (IOP) and a positive water drinking test. Furthermore, PACG could have been diagnosed in the presence of a partially occluded drainage angle and raised IOP or symptoms consistent with angle closure. ${ }^{13}$ These factors may draw the validity of the results into question.

In 1991, a Japanese multicentre collaborative group published results of a nationwide study of glaucoma prevalence. A target population of 16078 people aged 40 years and older was identified. Over a 2 year period, 8126 of this number were examined, giving a response rate of $50.5 \%$. All subjects underwent noncontact tonometry, optic disc photography, and a screening examination of the anterior segment at a slit lamp. In contrast with the study in China, the diagnosis of glaucoma status in this study was made on uniform criteria using a computer algorithm. Diagnosis of PACG required raised IOP and a narrow drainage angle (optic disc and visual field abnormalities were not necessary for the diagnosis). Primary glaucoma with an open angle was diagnosed on the basis of glaucomatous visual field loss in conjunction with suspected or definite glaucomatous changes of the optic disc. This category was further subdivided into POAG and normal tension glaucoma (NTG) depending on whether the presenting IOP was $\geqslant 21 \mathrm{~mm} \mathrm{Hg}$. Prevalence figures of $0.48 \%$ POAG, $2.1 \%$ NTG, and $0.21 \%$ PACG were cited for men, and for women rates were $0.6 \%$ POAG, $1.9 \%$ NTG, and $0.38 \%$ PACG (both sets of figures apply to the population aged 40 years and older). ${ }^{14}$

A study of Cape Malay people living in South Africa by Salmon et al marked a turning point in population research into PACG. The population was of mixed South East Asian and African heritage living in a single town. All 987 people in this study underwent a detailed examination, including gonioscopy. A significant finding was that symptoms consistent with intermittent angle closure were reported by three people. Asymptomatic PACG was diagnosed in 20 people, eight with glaucomatous optic neuropathy and a further 12 with full visual fields but an IOP $>21 \mathrm{~mm} \mathrm{Hg}$. Therefore, only eight of 23 (35\%) people with PACG had glaucomatous optic neuropathy affecting visual function. Three of these were blind in both eyes. The high rates of asymptomatic angle closure and severe visual loss in PACG have become recurring themes in the study of PACG in Asian people. ${ }^{15}$

The township of Jin Shan in rural Taiwan was the site of a population based study of screening techniques for PACG. This joint US-Taiwanese project, published in 1996, identified a target population of 5441 people aged 40 years and older, of whom $562(10.3 \%)$ were examined. A gonioscopic examination was carried out on all subjects. PACG was diagnosed in people with a "narrow" angle and either an IOP $>18 \mathrm{~mm} \mathrm{Hg}$, an increase in IOP 
Table 1 The rate of uniocular and binocular blindness affecting people with glaucomatous optic neuropathy in two east Asian populations

\begin{tabular}{llllll}
\hline & \multicolumn{3}{l}{ Rural Mongolia } & & \multicolumn{2}{l}{ Urban Singapore } \\
\cline { 2 - 3 } \cline { 6 - 6 } \cline { 5 - 6 } & Uniocular & Binocular & & Uniocular & Binocular \\
\hline POAG & $25 \%(1 / 4)^{\star}$ & $0 \%(0 / 4)$ & & $27 \%(6 / 22)$ & $9 \%(2 / 22)$ \\
PACG & $75 \%(6 / 8)$ & $38 \%(3 / 8)$ & & $50 \%(7 / 14)$ & $29 \%(4 / 14)$ \\
Secondary & $100 \%(2 / 2)$ & $0 \%(0 / 2)$ & & $71 \%(5 / 7)$ & $0 \%(0 / 7)$ \\
\hline
\end{tabular}

Blindness defined as VA $<3 / 60$ or severely constricted visual field.

*This subject was blind in one eye from glaucomatous optic neuropathy and from a macular branch retinal vein occlusion in the other.

Table 2 Population prevalence of people with occludable drainage angles, primary angle closure, those with glaucomatous optic neuropathy from angle closure

\begin{tabular}{llll}
\hline & All occludable angles & $\begin{array}{l}\text { Primary angle } \\
\text { closure (PAC) }\end{array}$ & $\begin{array}{l}\text { PAC with glaucomatous optic } \\
\text { neuropathy }(\text { PACG) }\end{array}$ \\
\hline Mongolia (rural) & $6.4 \%(4.3,8.5)$ & $2.0 \%(1.3,3.1)$ & $0.8 \%(0.4 .1 .7)$ \\
Singapore (urban) & $6.3 \%(4.9,7.6)$ & $2.2 \%(1.4,3.1)$ & $0.8 \%(0.4,1.2)$ \\
\hline
\end{tabular}

Rates given for the population aged 40 years and older.

Age and sex structure of both populations is very similar.

All occludable angles category includes those with PAC and PACG.

PAC category includes those with PACG.

$95 \%$ confidence intervals given in parentheses.

$\geqslant 8 \mathrm{~mm} \mathrm{Hg}$ on dark prone provocation test, or a previous "acute" episode of angle closure with an iridectomy. The diagnosis did not depend on the presence of a visual field defect or structural optic neuropathy. There were 17 people diagnosed as suffering PACG (3.0\%). Only $35 \%$ of cases gave a history of symptoms characteristic of "acute" angle closure. Two of these 17 people $(12 \%)$ were blind in both eyes. ${ }^{16}$

\section{Classification and description of cases}

Data from South Africa, Mongolia, Taiwan, and Singapore show that PACG among Asian people most often develops without the classic symptomatic episodes familiar to Western ophthalmologists. ${ }^{15-18}$ The current textbook classification of PACG places emphasis on symptomatology. As many symptomatic episodes of angle closure recover without visual loss (at least in the short term-the long term prognosis is unclear), ${ }^{19-21}$ this emphasis may be inappropriate. There is a growing recognition that, in attempting to classify the cases of angle closure to signify severity and project prognosis, more consideration should be given to signs of "end organ damage." Specifically, damage or obstruction of the trabecular meshwork and structural and functional indices of glaucomatous optic neuropathy (GON) should be the focus of classification. ${ }^{1822} 23$ "Primary angle closure" (PAC) is now considered the most appropriate term for people with synechial angle closure and/or raised intraocular pressure due to closure of the angle. When

Table 3 Estimated urban and rural population of China in 2001 aged 40 years and older

\begin{tabular}{lllllll}
\hline & \multicolumn{3}{l}{ Urban $\left(\times 10^{3}\right)$} & & \multicolumn{2}{l}{ Rural $\left(\times 10^{3}\right)$} \\
\cline { 2 - 3 } Age (years) & Men & Women & & Men & Women & Total $\left(\times 10^{3}\right)$ \\
\hline $40-49$ & 22185.9 & 15266.0 & & 61724.5 & 57972.3 & 162720.1 \\
$50-59$ & 15249.0 & 12140.8 & & 42425.1 & 39539.2 & 111425.1 \\
$60-69$ & 10373.6 & 7498.5 & & 28861.0 & 27766.0 & 76980.7 \\
$70-79$ & 5297.4 & 5978.5 & & 14738.3 & 16633.0 & 42647.2 \\
$80+$ & 1194.9 & 1995.8 & & 3324.4 & 5552.7 & 12067.9 \\
Total & 54301.0 & 53003.4 & & 151073.3 & 147463.3 & 405841.0 \\
\hline
\end{tabular}

Data: United States Census Bureau. ${ }^{26}$

Projected from age and sex specific data, assuming 0.2644 of population is urban.

Some columns may not add up exactly because of rounding of figures. considering PACG in the international context, the term "glaucoma" is probably best reserved for cases of primary angle closure and GON. ${ }^{24}$ The term "occludable angle" has been widely used in population surveys of glaucoma. The definition in most widespread use $\left(\geqslant 270^{\circ}\right.$ of the posterior, usually pigmented trabecular meshwork not seen) has been adopted by convention, rather than being evidence based. ${ }^{11} 15$ It now appears that this definition may be too stringent, and excludes many people with significant angle closure. ${ }^{25}$

\section{The number of people in China affected} by glaucoma and associated loss of vision During the course of collaborative research in Mongolia and Singapore we were able to carry out population surveys of glaucoma prevalence and risk factors. These projects have generated data on a relatively small number of glaucoma cases, and any attempt to extrapolate estimated glaucoma prevalence and blindness rates to a wider population must be carried out with caution. However, given the lack of data on for the world's most populous country, it is probably appropriate to make a tentative move in this direction. The prevalence figures and rates of visual loss revealed in these studies were consistent with our expectations, and strengthened our belief that the trends shown are accurate. In both populations, when GON had developed, PACG and secondary glaucoma cause a higher rate of uniocular visual impairment than POAG. In absolute terms, PACG was the leading cause of blindness in both eyes. In the small number of cases in these studies, secondary glaucoma did not cause any bilateral blindness. Table 1 outlines the rate of uniocular and binocular blindness (defined as visual acuity $<3 / 60$ or visual field constricted to $\leqslant 10^{\circ}$ ) in Mongolia and Singapore. ${ }^{17}{ }^{18}$ In Mongolia, there were 14 people with GON: four with POAG, eight with PACG, and two with secondary glaucoma. In Singapore, 22 cases were classified as POAG, 14 as PACG, and seven as secondary glaucoma. The Mongolia data have been reclassified in line with changing diagnostic criteria, reserving the term "glaucoma" for people with GON. ${ }^{23}$ Two people in each survey were diagnosed as cases of glaucoma, although it was not possible to determine the mechanism. These people were excluded from the statistical model, meaning that the figures presented in this paper are likely to be a conservative estimate.

Table 2 outlines the prevalence of people with "occludable" drainage angles, primary angle closure, and GON associated with PAC in Mongolia and Singapore. The similarities in prevalence rates in a developing country (Mongolia) and a country with a recently affluent population (Singapore) are striking. The age structure of these two populations is very similar.

In an attempt to estimate the number of people in China with occludable drainage angles, PAC, and PACG, we obtained mid-year population estimates for China in 2001, subdivided by decade age group and sex, from the US Census Bureau website (Table 3). ${ }^{26}$ 
Table 4 Estimated number of individuals with occludable drainage angles, primary angle closure, and glaucomatous optic neuropathy

\begin{tabular}{|c|c|c|c|c|c|c|c|c|}
\hline & \multicolumn{2}{|c|}{$\begin{array}{l}\text { Occludable angles } \\
\left(\times 10^{3}\right)\end{array}$} & \multicolumn{2}{|c|}{$\begin{array}{l}\text { Primary angle closure } \\
\left(\times 10^{3}\right)\end{array}$} & \multicolumn{2}{|c|}{$\begin{array}{l}\text { Primary angle } \\
\text { closure }+ \text { GON } \\
\left(\times 10^{3}\right)\end{array}$} & \multicolumn{2}{|c|}{$\begin{array}{l}\text { Incidence of symptomatic } \\
\text { primary angle closure } \\
\text { (peoplelyear) }\end{array}$} \\
\hline & Men & Women & Men & Women & Men & Women & Men & Women \\
\hline $40-49$ & 355 & 331 & 1 & 10 & 45.1 & 41 & 2349 & 40 \\
\hline $50-59$ & 2184.6 & 6098.2 & 716.1 & 1955.4 & 274.9 & 765.0 & 7613 & 18490 \\
\hline $60-69$ & 2748.3 & 5346.0 & 896.1 & 1714.0 & 345.6 & 670.6 & 10044 & 25818 \\
\hline $70-79$ & 3035.2 & 3331.5 & 968.0 & 1077.9 & 380.5 & 418.4 & 7994 & 18835 \\
\hline $80+$ & 684.6 & 1112.2 & 218.3 & 359.8 & 85.8 & 139.7 & 1803 & 6288 \\
\hline Subtotal & 9007.8 & 19200.4 & 2922.583 & 6157.5 & 1131.8 & 2408.6 & 29804 & 73530 \\
\hline Total & 28208.2 & & 9080.0 & & 3540.4 & & 103334 & \\
\hline
\end{tabular}

Number of people with occludable angles calculated for urban and rural areas by age and sex standardised rates from Singapore and Mongolia respectively, and includes people with PAC and PACG.

Number of people with PAC includes those with PACG.

All figures in thousands except incidence of symptomatic episodes.

Incidence of symptomatic, "acute" angle closure is expressed as cases per year.

Some columns may not add up exactly because of rounding of figures.

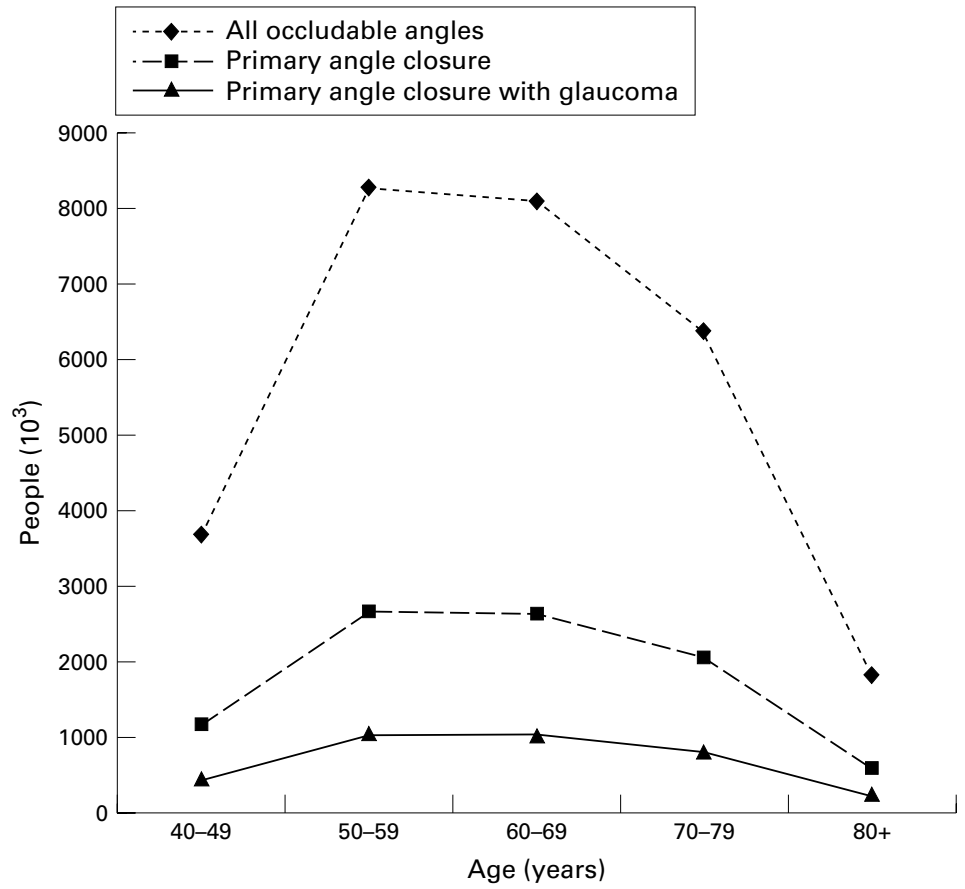

Figure 1 Angle closure glaucoma in China.

These data show that $26.44 \%$ of the population was urban. Therefore a 0.2644 weighting was applied to calculate the number of people in an urban environment. The remaining 0.7356 of the population was classed as rural. It was assumed that data from Mongolia were representative of rural China and those from Singapore were representative of urban China. The numbers of people with occludable angles were calculated using the age and sex specific rates for Mongolia and Singapore. ${ }^{17} 18$ The rate of PAC relative to the rate of occludable angles (for example, in Mongolia, 2.0/6.4 = 0.3125) was calculated for both urban and rural populations. This figure was then used to estimate the number of people with PAC from the number of people with occludable angles. The process was repeated using the ratio of people with PAC and GON to occludable angles (for example, in Mongolia, $0.8 / 6.4=0.125$ ), to estimate the number of people suffering PACG. These figures are given in Table 4 . This is illustrated graphically in Figure 1. This table also gives the number of people per year in China suffering symptomatic primary angle closure, extrapolated from data on Chinese Singaporeans. ${ }^{27}$

The total numbers of people in urban and rural China with GON were estimated using the age and sex specific rates of GON in Mongolia and Singapore, and US Census Bureau population data. The numbers of people with POAG, PACG, and secondary glaucoma were calculated as a fraction of the total with GON, using the ratio of people with these conditions in the two population surveys (for example, in Mongolia: PACG $=8 / 14=0.5714$ ). The numbers of people with uniocular and binocular blindness resulting from glaucoma were calculated using the estimated number of people with POAG, PACG, and secondary glaucoma, and the rates of visual loss given in Table 1 . Calculated figures are given in Table 5. The fact that these figures represent a rough estimate is highlighted by the difference between calculated number of PACG sufferers in Table 4 (3.5 million) and Table 5 (4.5 million).

\section{Can the problem be dealt with?}

Our data suggest that among China's 405 million adults aged 40 years and older there are somewhere in the region of 9.4 million adults with GON. Approximately 5.2 million people are blind in at least one eye, and 1.7 million of these are blind in both eyes as a consequence of this disease. If findings in Mongolia and Singapore are applicable to China, glaucoma probably accounts for almost as much blindness as does cataract. ${ }^{17} 1828$ PACG is probably responsible for the vast majority of bilateral glaucoma blindness, and therefore efforts to tackle blindness in China may not be fully successful unless the problem of glaucoma is addressed.

It has been shown that PAC can be detected before the onset of symptomatic episodes of

Table 5 Estimated number of people in China affected by glaucoma, giving number of uniocular and binocular blind

\begin{tabular}{|c|c|c|c|c|c|c|c|c|c|}
\hline & \multicolumn{3}{|c|}{ Rural China $\left(\times 10^{3}\right)$} & \multicolumn{3}{|c|}{ Urban China $\left(\times 10^{3}\right)$} & \multicolumn{2}{|c|}{$\begin{array}{l}\text { Total } \\
\text { (urban and rural, } \times 10^{3} \text { ) }\end{array}$} & \multirow[b]{2}{*}{$\begin{array}{l}\text { Blind in } \\
\text { both eyes }\end{array}$} \\
\hline & Glaucoma & $\begin{array}{l}\text { Blind in } \\
\text { one eye }\end{array}$ & $\begin{array}{l}\text { Blind in } \\
\text { both eyes }\end{array}$ & Glaucoma & $\begin{array}{l}\text { Blind in } \\
\text { one eye }\end{array}$ & $\begin{array}{l}\text { Blind in } \\
\text { both eyes }\end{array}$ & Glaucoma & $\begin{array}{l}\text { Blind in } \\
\text { one eye }\end{array}$ & \\
\hline POAG & 1680.5 & 420.1 & 0 & 1794.4 & 489.4 & 163.1 & 3474.8 & 909.5 & 163.1 \\
\hline PACG & 3360.9 & 2520.7 & 1260.4 & 1141.9 & 570.9 & 326.2 & 4502.8 & 3091.6 & 1586.6 \\
\hline Secondary & 840.2 & 840.2 & 0 & 570.9 & 407.8 & 0 & 1411.1 & 1248.0 & 0 \\
\hline Total & 5881.6 & 3781.1 & 1260.4 & 3507.2 & 1468.1 & 489.4 & 9388.8 & 5249.2 & 1749.7 \\
\hline
\end{tabular}

All figures in thousands, relating to the population aged 40 years and older

Glaucoma affected indicates number of individuals with glaucomatous optic neuropathy in at least one eye.

${ }^{\star}$ One eye is number of people blind in at least one eye, and therefore includes those who are blind in both eyes.

Blindness defined as VA $<3 / 60$ or visual field constricted to $\leqslant 10^{\circ}$. 
GON using various rapid detection tests. ${ }^{16} 2930$ Once detected, the optimal timing and nature of the intervention remain unproved. To achieve widespread success in rural areas, where the majority of people with PAC live, this means a simple, cheap, one time only intervention. Surgical and laser treatment therefore seem the most appropriate. Laser iridotomy and surgical iridectomy probably offer effective methods of dealing with pupil block PAC, which we believe accounts for at least $90 \%$ of cases in Mongolia. ${ }^{17}{ }^{31}$ However, there are reports of significant problems with nonpupil block PAC in hospital based practice in Taiwan. ${ }^{32}{ }^{33}$ It has also been shown that laser peripheral iridotomy (PI) is a suboptimal method of managing PAC where GON has developed..$^{3135}$ The role of lens extraction in the management of PAC remains to be investigated in detail. ${ }^{36-38}$

\section{The future of glaucoma blindness prevention in east Asia}

The available data show that glaucoma is a major cause of blindness in east Asia. The figures calculated here should not be seen as an accurate projection, but rather as an estimate of the approximate size of the problem. There is good evidence that PACG may be detected at an early stage, and it may be amenable to laser iridotomy. However, the number of robust studies examining the performance of screening tests is small. Further work in this area is necessary, ideally in the community setting. The exact treatment that should be offered as prophylaxis needs to be investigated further, to evaluate both safety and efficacy. If Western policies on the role of laser iridotomy ${ }^{39}$ are extrapolated to China, there are probably 28 million people who should have a laser iridotomy. A more conservative approach (treating people with PAC) would still require treatment of around 9.1 million. Clearly, a small risk of treatment causing harm (for example, corneal endothelial damage from YAG laser iridotomy being performed by medical personnel without an appropriate level of training) when applied to the massive numbers that may need to be treated, could translate into a significant number of people suffering iatrogenic loss of vision.

We envisage a series of randomised trials of screening and prophylactic laser PI taking place in Chinese communities throughout Asia to assess the optimal performance of preventive treatment. It is likely that such trials will need sample sizes of between 5000 and 10000 people followed for approximately 10 years. One such study of 4725 people aged 50 years and older is already under way in Mongolia. ${ }^{40}$ If intervention is proved to be safe and effective the emphasis would then shift to operational research, examining the appropriate staffing development, equipment requirements, and development of quality control systems. In order for this strategy to be evidence based, we have laid out a research timetable of approximately 15 years, requiring several large randomised, controlled trials to be performed in east Asia. The scale of the problem is daunting.
However, we may now look forward with considerable optimism to the prospect of developing strategies to prevent blindness from PACG in Asia.

1 Thylefors B, Négrel AD. The global impact of glaucoma. Bull World Health Organ 1994;72:323-6.

2 Quigley HA. Number of people with glaucoma worldwide. Br f Ophthalmol 1996;80:389-93.

3 World Health Organization. Causes of blindness worldwide. http://www.who.int $/ \mathrm{pbd} / \mathrm{pbl} / \mathrm{data} / \mathrm{blindness \_ world}$ prevalence_1997.pdf.1998.

4 Thylefors B. A global initiative for the elimination of avoidable blindness. Am F Ophthalmol 1998;125:90-3.

5 Taylor HR, Keeffe J. World blindness: a 21st century perspective. Br f Ophthalmol 2001;85:261-6.

6 Foster A. Cataract and "Vision 2020-the right to sight" Foster A. Cataract and "Vision 2020 - the
initiative. Br 7 Ophthalmol 2001;85:635-9.

7 Tielsch JM, Katz J, Singh K, et al. A population-based evaluation of glaucoma screening: the Baltimore Eye Survey. Am f Epidemiol 1991;134:1102-10.

8 Wormald RPL. Primary open angle: screening. In: Hitchings RA, ed. Glaucoma. London: BMJ Publishing Group, 2000

9 Clemmesen V, Alsbirk PH. Primary angle-closure glaucoma (ACG) in Greenland. Acta Ophthalmol 1971;49:47-58.

10 Alsbirk PH. Anterior chamber depth and primary angleclosure glaucoma. I. An epidemiologic study in Greenland Eskimos. Acta Ophthalmol 1975;53:89-104.

11 Arkell SM, Lightman DA, Sommer A, et al. The prevalence of glaucoma among eskimos of Northwest Alaska. Arch of glaucoma among eskimo

12 Van Rens GHMB, Arkell SM, Charlton W, et al. Primary angle-closure glaucoma among Alaskan Eskimos. Doc Ophthalmol 1988;70:265-76.

$13 \mathrm{Hu} \mathrm{Z}$, Zhao ZL, Dong FT. [An epidemiological investigation of glaucoma in Beijing and Shun-yi county]. [Chinese] Chung-Hua Yen Ko Tsa Chih [Chinese fournal of Ophthalmology] 1989;25:115-18.

14 Shiose Y, Kitazawa Y, Tsukuhara S, et al. Epidemiology of glaucoma in Japan-a nationwide glaucoma survey. $\mathfrak{f p}_{p} \mathfrak{f}$ Ophthalmol 1991;35:133-55.

15 Salmon JF, Mermoud A, Ivey A, et al. The prevalence of primary angle-closure glaucoma and open angle glaucoma in Mamre, Western Cape, South Africa. Arch Ophthalmol 1993;111:1263-9

16 Congdon N, Quigley HA, Hung PT, et al. Screening techniques for angle-closure glaucoma in rural Taiwan. techniques for angle-closure gla

17 Foster PJ, Baasanhu J, Alsbirk PH, et al. Glaucoma in Mongolia-a population-based survey in Hövsgöl Province, northern Mongolia. Arch Ophthalmol 1996;114: 1235-41

18 Foster PJ, Oen FT, Machin DS, et al. The prevalence of glaucoma in Chinese residents of Singapore. A crosssectional population survey in Tanjong Pagar district. Arch Ophthalmol 2000;118:1105-11.

19 Douglas GR, Drance SM, Schulzer M. The visual field and nerve head in angle-closure glaucoma. A comparison of the effects of acute and chronic angle closure. Arch Ophthalmol 1975;93:409-11.

20 Dhillon B, Chew PT, Lim ASM. Field loss in primary angle-closure glaucoma. Asia-Pac $\mathcal{F}$ Ophthalmol 1990;2:85-

21 Aung T, Looi AL, Chew PT. The visual field following acute primary angle closure. Acta Ophthalmol Scand 2001;79: 298-300.

22 Foster PJ, Johnson GJ. Primary angle-closure- classification and clinical features. In: Hitchings RA, ed. Glaucoma. London: BMJ Publishing Group, 2000.

23 Foster PJ, Buhrmann RR, Quigley HA, et al. The definition of glaucoma in prevalence surveys. $\mathrm{Br} \mathcal{F}$ Ophthalmol 2001;85: (in press)

24 American Academy of Ophthalmology. Primary angleclosure. In: Caprioli J, et al, eds. Preferred practice patterns. San Francisco: AAO, 2000.

25 Nolan WP, Aung T, Chan YH, et al. The relationship between gonioscopic angle width and prevalence of synechial damage to the drainage angle in two East Asian populations. Invest Ophthamol Vis Sci (ARVO Suppl) 2001; 42:S102 (Abstract).

26 United States Census Bureau. Urban and rural population of China. http://www.census.gov/ipc/www/idbsprd.html. United States Government, 2001.

27 Seah SKL, Foster PJ, Chew PT, et al. Incidence of acute primary angle-closure glaucoma in Singapore. An island-wide survey. Arch Ophthalmol 1997;115:1436-40.

8 Baasanhu J, Johnson GJ, Burendei G, et al. Prevalence and causes of blindness and visual impairment in Mongolia: a survey of populations aged 40 years and older. Bull World Health Organ 1994;72:771-6.

29 Foster PJ, Devereux JG, Alsbirk PH, et al. Detection of gonioscopically occludable angles and primary angle losure 2000;84: 186-92.

30 Devereux JG, Foster PJ, Baasanhu J, et al. Anterior chamber depth measurement as a screening tool for primary angle-
closure glaucoma in an East Asian population. Arch Ophthalmol 2000;118:257-63. 
31 Nolan WP, Foster PJ, Devereux JG, et al. YAG laser iridotomy treatment for primary angle-closure in east Asian iridotomy treatment for primary angle-clo

32 Hung PT, Chou LH. Provocation and mechanism of angleclosure glaucoma after iridectomy. Arch Ophthalmol 1979 97:1862-4

33 Hung PT. Aetiology and mechanism of primary angleclosure glaucoma. Asia-Pac $\mathcal{F}$ Ophthalmol 1996;2:82-4.

34 Yamamoto T, Shirato S, Kitazawa Y. Treatment of primary angle-closure glaucoma by argon laser iridotomy: long-term follow-up study. Fpn $\mathcal{F}$ Ophthalmol 1985;29:1-12

35 Salmon JF. Long-term intraocular pressure control after Nd-YAG laser iridotomy in chronic angle-closure glaucoma. F Glaucoma 1993;2:291-6.

36 Greve EL. Primary angle-closure glaucoma: extracapsular cataract extraction or filtering procedure? Int Ophthalmol 1988;12:157-62.
37 Acton J, Salmon JF, Scholtz R. Extracapsular cataract extraction with posterior chamber lens implantation in primary angle-closure glaucoma. F Cataract Refract Surg 1997; 23:930-4.

38 Teekhasaenee C, Ritch R. Combined phacoemulsification and goniosynechialysis for uncontrolled chronic anglelosure glaucoma after acute angle-closure glaucoma. Ophthalmology 1999;106:669-74.

39 Ritch R. Definitive signs and gonioscopic visualization of appositional angle closure are indications for prophylactic laser iridectomy. Surv Ophthalmol 1996;41:33-6.

40 Nolan WP, Ganzorig S, Undraa A, et al. Randomised controlled trial of screening for primary angle-closure in Mongolia. Invest Ophthalmol Vis Sci 2000;41:S476 (Abstract). 